\title{
IDENTIFICATION OF GROWTH HORMONE RECEPTOR IN PLEXIFORM NEUROFIBROMAS OF PATIENTS WITH NEUROFIBROMATOSIS TYPE 1
}

\author{
Karin Soares Gonçalves Cunha, Eliane Porto Barboza, Eliene Carvalho da \\ Fonseca
}

Cunha KSG, Barboza EP, da Fonseca EC. Identification of growth hormone receptor in plexiform neurofibromas of patients with neurofibromatosis type 1. Clinics. 2008;63(1);39-42.

OBJECTIVE: The aim of this study was to investigate the presence of growth hormone receptor in plexiform neurofibromas of neurofibromatosis type 1 patients.

INTRODUCTION: The development of multiple neurofibromas is one of the major features of neurofibromatosis type 1. Since neurofibromas commonly grow during periods of hormonal change, especially during puberty and pregnancy, it has been suggested that hormones may influence neurofibromatosis type 1 neurofibromas. A recent study showed that the majority of localized neurofibromas from neurofibromatosis type 1 patients have growth hormone receptor.

METHODS: Growth hormone receptor expression was investigated in 5 plexiform neurofibromas using immunohistochemistry. RESULTS: Four of the 5 plexiform neurofibromas were immunopositive for growth hormone receptor.

CONCLUSION: This study suggests that growth hormone may influence the development of plexiform neurofibromas in patients with neurofibromatosis type 1 .

KEYWORDS: Von Recklinghausen’s disease. Immunohistochemistry. Puberty.

\section{INTRODUCTION}

Neurofibromatosis type 1 (NF1), also known as von Recklinghausen's disease, is an autosomal dominant disorder caused by mutations in the NF1 gene, which is located on chromosome 17q11.2. ${ }^{1,2} \mathrm{NF} 1$ is the most common form of neurofibromatosis (NF) and is one of the most frequently occurring human genetic diseases, with a prevalence of 1 in 3,000 births.

Neurofibromas, café-au-lait spots, freckling in the inguinal and axillary regions and Lisch nodules develop in most affected patients. ${ }^{1,4}$ The defining feature of NF1 is the development of multiple neurofibromas. ${ }^{2,5}$ In clinical terms,

Fluminense Federal University, Medicine School, Postgraduate program of pathology - Niterói/RJ, Brazil. karingoncalves@terra.com.br

Received for publication on October 15, 2007.

Accepted for publication on October 19, 2007. these tumors can be classified into two major groups: localized (or discrete) and plexiform. ${ }^{2.5}$ Localized neurofibromas are the most common type of neurofibroma in NF1, and present as a focal mass with well-defined margins. ${ }^{2,5}$ Most of these tumors begin to appear in later childhood, especially in early puberty. ${ }^{2,5}$ Their number varies widely between patients and tends to increase over time. ${ }^{2,5}$ In spite of their presence in large numbers, localized neurofibromas rarely, if ever become malignant. ${ }^{5}$

Plexiform neurofibromas are almost always associated with NF1 and occur in only about $30 \%$ of all patients. They are the main source of morbidity in NF1 individuals, due to their tendency to grow to large sizes and their capacity to cause significant deformity. ${ }^{2,5,6}$ Malignant transformation into malignant peripheral nerve sheath tumors (MPNST) occurs in 4\% of these tumors and is the main cause of mortality in adult patients with NF1. ${ }^{2,5,6}$ Plexiform neurofibromas are thought to be congenital in origin, 
and those that involve the skin usually become visible within the first two years of life. ${ }^{5,6,7}$

Based on the observation that neurofibromas commonly increase in size and number during periods of hormonal change, especially during puberty and pregnancy, it has been suggested that hormones may influence neurofibroma growth in NF1 patients. $8,9,10,11,12,13$

Since high plasma levels of growth hormone $(\mathrm{GH})$ occur during adolescence, it is possible that this hormone may influence the growth of neurofibromas in NF1 individuals. Our previous study showed that most patients with NF1 have localized neurofibromas that express growth hormone receptor (GHR), suggesting that $\mathrm{GH}$ may play a role in the development of these neoplasms. ${ }^{12}$ The aim of this study was to investigate the presence of GHR in plexiform neurofibromas of NF1 patients.

\section{METHODS}

This study was approved by the ethics committee of Fluminense Federal University, Brazil.

\section{Patients}

Five plexiform neurofibromas from NF1 patients were retrieved from the files of the pathological anatomy service of Antônio Pedro University Hospital of Fluminense Federal University (Table 1).

Table 1 - Clinical data from patients

\begin{tabular}{lcccl}
\hline Case & Age $(\mathrm{yr})$ & Sex & Race & Localization \\
\hline 1 & 19 & F & W & Genital (skin) \\
2 & 9 & F & W & Front (skin) \\
3 & 43 & F & B & Nose (skin) \\
4 & 14 & F & B & Abdomen (skin) \\
5 & 21 & F & B & Supra orbit region (skin) \\
\hline
\end{tabular}

$\mathrm{W}=$ white $\mathrm{B}=$ black

All patients included in this study were diagnosed with NF1 according to the diagnostic criteria established at the 1987 National Institutes of Health (NIH) Consensus Development Conference on Neurofibromatosis ${ }^{14}$ (Table 2).

\section{Immunohistochemistry}

Serial $5 \mu \mathrm{m}$ sections were cut from paraffin wax blocks and collected on silane-coated slides. After dewaxing, GHR presence was detected immunohistochemically using the EnVision kit ${ }^{\mathrm{TM}}$ (code K1392; Dako, Capenteria, California, USA). Briefly, antigen retrieval was performed
Table 2 - Diagnostic criteria for Neurofibromatosis type 1 (NF1) established by the National Institutes of Health Consensus Development Conference (1988) ${ }^{15}$

Individual is affected with NF1 if two or more of the following conditions are met:

- Six or more café au lait macules over $5 \mathrm{~mm}$ in greatest diameter in prepubertal individuals and over $15 \mathrm{~mm}$ in greatest diameter in post-pubertal individuals.

- Two or more neurofibromas of any type, or one plexiform neurofibroma.

- Freckling in the axillary or inguinal regions.

- Optic glioma.

- Two or more Lisch nodules (iris hamartomas).

- A distinctive osseous lesion such as sphenoid dysplasia or thinning of long bone cortex, with or without pseudoarthrosis.

- A first-degree relative with NF1 by the above criteria.

using a microwave oven and citrate buffer in a pressure cooker. Endogenous peroxidase activity was eliminated by incubation for 10,15 and 20 minutes in $6 \% \mathrm{H}_{2} \mathrm{O}_{2}$ in distilled water at room temperature. Non-specific protein binding was blocked by incubation with a 1/100 dilution of normal goat serum in antibody diluent with background reducing component (code S3022; Dako) for 30 minutes at $37{ }^{\circ} \mathrm{C}$. Sections were incubated: (1) overnight at $4{ }^{\circ} \mathrm{C}$ with a $1 / 100$ dilution of the primary monoclonal antibody against GHR (263; code MCA 1555; Serotec, Raleigh, North Carolina, USA); or (2) for one hour at room temperature with EnVision ${ }^{\mathrm{TM}}$. Visualization of bound antibody was performed by incubation for 5 minutes in diaminobenzidine. Between each step, sections were washed three times for 10 minutes in Tris buffered saline. All incubations were carried out in humidified chambers to prevent evaporation. Sections were counterstained in Mayer's haematoxylin and coverslipped with Entellan (code 107961; Merck, Frankfurt, Bradenburg, Germany). Negative controls were performed by omitting the primary monoclonal antibody, and normal fetus bone marrow was used as a positive control.

\section{RESULTS}

Sections of normal epidermis and dermal appendages showed immunoreactivity for GHR and served as positive internal controls. All layers of the epidermis showed immunopositivity for GHR, except for the keratin layer. Hair follicles and sebaceous glands were also GHR immunopositive. The excretory ducts of sweat glands showed immunoreactivity only in the basal cells, and no immunoreaction was seen in the cells of the secretory portion of sweat glands. Vascular endothelial cells and skeletal muscle cells also possessed GHR immunoreactivity.

The control sections were negative for GHR. 
Table 3 - Results of immunohistochemical analyses for GHR

\begin{tabular}{lllll}
\hline Case & GHR & Localization of immunoreaction & Pattern of immunoreaction & Distribution of immunoreaction \\
\hline 1 & + & C; N & granular & homogeneous \\
2 & + & C $;$ N $;$ CM & heterogeneous \\
3 & - & & granular & heterogeneous \\
4 & + & C; CM & granular & homogeneous \\
5 & + & C $\mathrm{N}$ & & \\
\hline
\end{tabular}

$\mathrm{C}=$ cytoplasm $; \mathrm{CM}=$ cellular membrane $\mathrm{N}=$ nucleus

\section{Immunohistochemical analyses in neurofibromas}

Of the five plexiform neurofibromas studied, four were immunopositive for GHR. In two plexiform neurofibromas, staining was seen only in the nucleus and cytoplasm. One plexiform neurofibroma had immunoreactivity associated with the nucleus and cellular membrane. In the other immunopositive plexiform neurofibromas, the immunoreactivity could be detected in the nuclei, cytoplasm and cellular membrane. Staining was granular in all neurofibromas. In two of the four immunopositive neurofibromas, the pattern of staining was heterogeneous, whereas in the remaining two, the staining had a homogeneous distribution.

Table 3 summarizes the results of the immunohistochemical analysis of plexiform neurofibromas. Figure 1 shows typical GHR immunohistochemistry results.

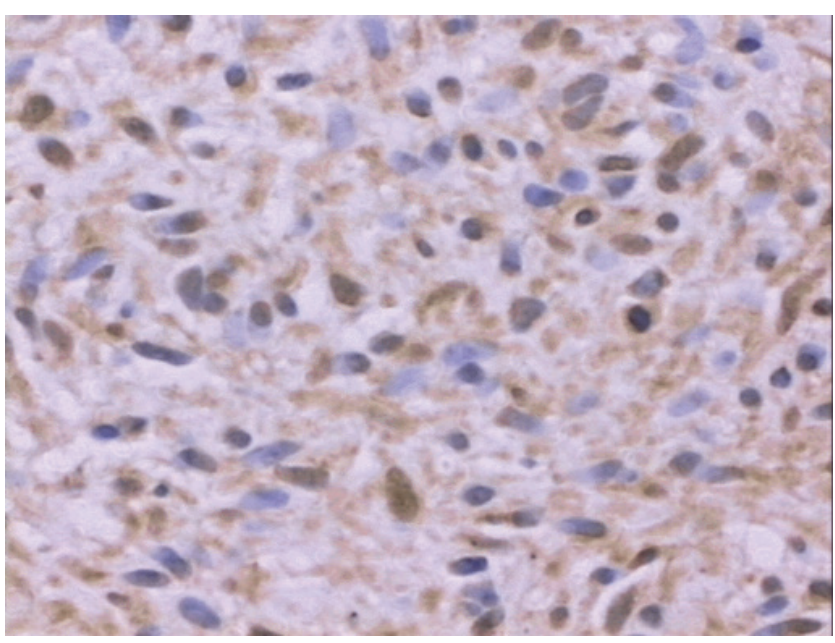

Figure 1 - Plexiform neurofibroma immunopositive for GHR (case number 5); 40x, immunohistochemistry.

\section{DISCUSSION}

Neurofibromin, the protein transcribed by the NF1 gene, contains a region that has high similarity to Ras-specific GTPase-activating proteins (GAPs). ${ }^{15}$ Both neurofibromin and GAP reduce cell proliferation by accelerating the inactivation of the Ras protein, which has a pivotal role in mitogenic intracellular signaling pathways. ${ }^{16}$ Therefore, mutations in the NF1 gene cause an increased risk of developing both benign (mainly neurofibromas) and malignant neoplasms (mainly MPNST), supporting the classification of NF1 as a tumor predisposition syndrome. ${ }^{2,5}$

$\mathrm{GH}$ acts on cells by binding to GHR and can activate a variety of signaling pathways to exert its effects upon mitogenesis, differentiation and metabolism. ${ }^{17}$ Interestingly, the Ras pathway, which is altered in NF1 patients, is one of the pathways used by GH. ${ }^{18,19}$

In the present study, it was observed that four of five plexiform neurofibromas from NF1 patients expressed GHR. Therefore, high levels of GH during puberty could cause the growth of these neoplasms.

Lincoln et al. ${ }^{30}$ verified using immunohistochemistry, that the ratio of immunopositive cells for GHR was higher in neoplasias than in normal tissues. An increased incidence of benign and malignant neoplasias has been detected in individuals with acromegaly. ${ }^{20,21,23,24,31} \mathrm{~A}$ role for $\mathrm{GH}$ in neoplastic dissemination has also been suggested, since it was observed that patients with prostate cancer who developed metastases had higher serum concentrations of $\mathrm{GH}$ than patients without metastases. ${ }^{25}$ An increased incidence of leukemia has also been reported in individuals treated with recombinant $\mathrm{GH}^{22,32}$

NF1 patients may have short stature, and some NF1 children with short stature of unknown cause have been treated with recombinant GH. ${ }^{33}$ Since many studies have suggested that $\mathrm{GH}$ is a potent inducer of cell growth in many neoplasias, the safety of GH in NF1 patients has been questioned. . $^{20-32}$

The presence of GHR in plexiform neurofibromas does not necessarily prove that this hormone plays a role in the development of plexiform neurofibromas in NF1 patients, but their presence at least suggests the capacity of these lesions to respond to $\mathrm{GH}$. Therefore, recombinant $\mathrm{GH}$ should be used with caution when treating short stature NF1 children, especially those who have plexiform neurofibroma. It is important to emphasize that plexiform neurofibroma is the most common precursor of MPNST, which has a very poor prognosis, and previous studies have suggested that GH may influence the development of other malignant neoplasms. ${ }^{2,5,6,21,22,25,26,27,28,29,31,32}$ 


\section{CONCLUSIONS}

Our results show that most plexiform neurofibromas expressed GHR. Therefore, it is possible that GH may in- fluence the development of these tumors. Although the concept that GH can stimulate the growth of neurofibromas in NF1 patients is still only a theory, the potential role of $\mathrm{GH}$ in the development of these lesions cannot be ignored.

\section{REFERENCES}

1. Friedman JM. Neurofibromatosis 1. Clinical Genetics. In:Friedman JM, Gutmann DH, Maccollin M et al, editors Neurofibromatosis. Phenotype, Natural History and Pathogenesis. Baltimore:the Johns Hopkins University Press, 1999, p. 110-8.

2. Geller M, Bonalumi Filho A. Neurofibromatose:clínica, genética e terapêutica. Rio de Janeiro:Guanabara Koogan; 2004

3. Huson SM, Compston DA, Harper PS. A genetic study of von Recklinghausen neurofibromatosis in South East Wales. II. Guidelines for genetic counselling. J Med Genet. 1989;26:712-21.

4. Park VM, Pivnick EK. Neurofibromatosis type 1 (NF1): a protein truncation assay yielding identification of mutations in $73 \%$ of patients. J Med Genet.1998;35:813-20.

5. Korf BR. Neurofibromatosis 1. Neurofibromas and malignant tumors of the peripheral nerve sheath. In: Friedman JM, Gutmann DH, Maccollin M, et al, eds. Neurofibromatosis. Phenotype, Natural History and Pathogenesis. Baltimore:the Johns Hopkins University Press;1999, p. 142-61.

6. Korf BR. Plexiform neurofibromas. Am J Med Genet. 1999;89:31-7.

7. Crawford AH, Schorry EK. Neurofibromatosis update. J Pediatr Orthop. 2006;26:413-23.

8. Dugoff L, Sujansky E. Neurofibromatosis type 1 and pregnancy. Am J Med Genet.1996;66:7-10.

9. Lammert M, Mautner VF, Kluwe L. Do hormonal contraceptives stimulate growth of neurofibromas? A survey on $59 \mathrm{NF} 1$ patients. BMC Cancer. 2005;9;5:16.

10. Martuza RL, Maclaughlin DT, Ojemann RG. Specific estradiol binding in schawnnomas, meningiomas and neurofibromas. Neurosurgery. 1981;9:665-71.

11. Chaudhuri PK, Walker MJ, Das Gupta TK, Beatties CW. Steroid receptors in tumors of nerve sheath origin. J Surgical Oncology. 1982;20:205-6.

12. Cunha KS, Barboza EP, Da Fonseca EC. Identification of growth hormone receptor in localised neurofibromas of patients with neurofibromatosis type 1. J Clin Pathol. 2003;56(10):758-63.

13. McLaughlin ME, Jacks T. Progesterone receptor expression in neurofibromas.Cancer Res. 2003;63:752-5.

14. Neurofibromatosis. NIH Consens Statement. 1987;6(12):1-19.

15. Shen HS, Harper, Upadhyaya M. Molecular genetics of neurofibromatosis type 1 (NF1). J Med Genet. 1996;33:2-17.

16. Klose A, Ahmadian M R, Shuelke M et al. Selective desactivation of neurofibromin GAP activity in neurofibromatosis type 1 (NF1). Hum Mol Genet. 1998;7:1261-8,

17. Billestrup N, Hansen JA, Hansen LH, et al. Molecular mechanism of growth hormone signaling. Endocr J. 1998;45:s41-5.
18. Carter-Su C, Rui L, Stofega MR. SH2-B and SIRP:JAK2 binding proteins that modulate the actions of growth hormone. Recent Prog Horm Res, 2000;55:293-311.

19. Kopchick JJ, Andry JM. Growth hormone (GH), GH receptor, and signal transduction. Mol Genet Metab, 2000;71:293-314

20. Alexander L, Appleton D, Hall R Ross WM, Wilkinson R. Epidemiology of acromegaly in the Newcastle region. Clin Endocrinol. 1980;12:71-9.

21. Andrews GS. Growth hormone and malignancy. J Clin Pathol. 1983;36:935-7.

22. Aktan M, Tanakol R, Nalcaci M, Dilcol G. Leukemia in a patient treated with growth hormone. Endocr J. 2000;47:471-3.

23. Barzilay J, Heatley GJ, Cushing G W. Benign and malignant tumors in patients with acromegaly. Arch Intern Med. 1991;151:1629-32.

24. Bengtsson BA, Edén S, Ernest I, Oden A, Sjogren B. Epidemiology and long-term survival in acromegaly: a study of 166 cases diagnosed between 1955 and 1984. Acta Med Scand. 1988;223:327-35.

25. British Prostate Study Group. Evaluation of plasma hormone concentrations in relation to clinical staging in patients with prostate cancer. Br J Urol. 1979;51:382-9.

26. Emerman JT, Leahy M, Gout PW. Elevated growth hormone levels in sera from breast cancer patients. Horm Metab Res.1985;17:421-4.

27. Garcia-Caballero T, Mertani H M, Lambert A et al. Increased expression of growth hormone and prolactin receptors in hepatocellular carcinomas. Endocrine. 2000;12:265-71.

28. Ginarte M, Garcia-Callabero T, Fernandez-Redondo V et al. Expression of growth hormone receptor in benign and malignant cutaneous proliferative entities. J Cutan Pathol. 2000;27:276-282.

29. Kaulsay K K, Zhu T, Bennett W Lee KO, Lobie PE. The effects of autocrine human growth hormone (hGH) on human mammary carcinoma cell behavior are mediated via the hGH receptor. Endocrinology. 2001;142:767-77.

30. Lincoln D T, Sinowatz F, Temmim-Baker L, Baker HI, Kolle S, Waters MJ. Growth hormone receptor expression in the nucleus and cytoplasm of normal and neoplastic cells. Histochem Cell Biol. 1998;109:141-59.

31. Ratner RE, Hare JW. Association of acromegaly and chondrosarcoma. South Med J. 1983;76:1181-82.

32. Watanabe S, Mizuno S, Oshima LH Tsunematsu Y, Fujimoto J, Komiyama A. Leukemia and other malignancies among GH users. J Pediatr Endocrinol. 1993;6:99-108.

33. Saenger P. Growth hormone in von Recklinghausen's disease:reckless or recommended? J Pediatr. 1998;133:172-4. 